Short Communication

\title{
Cutaneous leishmaniasis: an epidemiological survey in Iran during 2013-2015
}

\author{
Farhood Nikouee ${ }^{1}$, Mitra Soltanian², Farzin Babaee ${ }^{3}$, Mohadeseh Motamed-Jahromi ${ }^{4 *}$
}

(Received: 12 Dec 2016; Accepted: 13 Apr 2017)

\begin{abstract}
Background and Purpose: Cutaneous leishmaniasis is an endemic disease in different parts of Iran. The aim of this study was to investigate the epidemiology of cutaneous leishmaniasis in Zarrin Dasht, Fars, Iran, during 2013-2015.

Methods: This descriptive, cross-sectional study was performed on 266 patients selected through census sampling method. Data such as gender, age, occupation, disease season, location of scar on the patient's body, and place of residence were gathered using a checklist and analyzed through descriptive statistics and nonparametric methods.

Results: In this study, the majority of the patients were female (58.3\%) within the age group of 0-5 years (66.2\%), living in rural areas (53\%). The highest incidence rate was observed in autumn (49.2\%). The majority of lesions (49\%) were observed in face.

Conclusion: The results of this study showed that cutaneous leishmaniasis is an endemic disease in Zarrin Dasht, and it annually infects numerous people. Although the disease process has been declining during 2013-2015 in this region, this disease is still a health hazard and needs to be managed.
\end{abstract}

Keywords: Cutaneous leishmaniasis, Endemic, Epidemiology

\section{Introduction}

Leishmaniasis, a zoonotic disease, exists in all parts of the world and occurs in the form of cutaneous and visceral (kala-azar). This disease has a variety of cutaneous and mucosal manifestations (1). Inflamed pimples caused by cutaneous leishmaniasis become wounded and infected after a while, and in case of an inappropriate treatment, adverse effects and lesions will emerge on the nose, eyelids, and earlobes, which require heavy and costly treatment (2).
According to the reports of the World Health Organization, leishmaniasis is endemic in 98 countries, and more than 350 million people are at its risks (3). Out of the 22 countries in the MiddleEast, leishmaniasis exists in 14 of them. It is one of the most important and the second most common parasitic disease (after malaria) transmitted by arthropods and is native to Iran (4). More than 90\% of cases of leishmaniasis occur in 88 Iranian cities, and it is transferred in 17 provinces; the rural type

\footnotetext{
${ }^{1}$ Department of Community Medicine, Fasa University of Medical Sciences, Fasa, Iran

${ }^{2}$ School of Nursing and Midwifery, Shiraz University of Medical Sciences, Shiraz, Iran

${ }^{3}$ Fasa University of Medical Sciences, Fasa, Iran

4,* Corresponding author: School of Nursing, Fasa University of Medical Sciences, Fasa, Iran. Email: mohadesehmotamed@yahoo.com
} 
is widespread in 15 provinces of Iran, while the urban type affects almost all of the country's urban zones (5). The results of a study performed in 31 Iranian provinces during 2011-2013 reported that the highest incidence rate was in 2011 (27.5 per 100000 people) (6).

An epidemiological investigation on cutaneous leishmaniasis in the city of Torbat-e Jam showed that among the 855 samples, 504 (58.9\%) had positive test results for the disease, and the highest number of cases was recorded in 2011 with 204 cases (40.5\%) (7). A study showed that Ilam Province has changed from an endemic region to a hyper-endemic one, indicating the urgent need for more preventive measures (8). The results of a study in Zarrin Dasht, Fars Province, Iran, indicated that earthquakes led to outbreak of cutaneous leishmaniasis from April 2002 to April 2004 (9). Although prevention of leishmaniasis in different populations is of great importance and there is a shortage of information regarding its epidemiology and threats in Zarrin Dasht town, no related study was conducted on this issue in the recent years in this district. Therefore, we aimed to investigate epidemiological features of leishmaniasis based on demographic and geographical characteristics of cutaneous leishmaniasis in Zarrin Dasht, Fars Province, Iran.

\section{Materials and Methods}

This cross-sectional, descriptive-analytical study was carried out on 266 patients with cutaneous leishmaniasis, who referred to Zarrin Dasht Health Center between April 2013 and March 2015. The subjects were selected through census sampling, and the data collection was performed using checklists and records of each patient in Zarrin Dasht Health Center.

This study analyzed the cases of cutaneous leishmaniasis disease in terms of place of residence, gender, age, occupation, disease season, location of scar on the patient's body, type of drinking water, and the proliferation location of mosquitoes.

The data analysis was performed using descriptive statistics, including mean, median, and standard deviation, frequency, and frequency percentage. The mean ages in the subgroups were compared using Mann-Whitney $U$ test in SPSS, version 18. P-value less than 0.05 was considered statistically significant.

\section{Results}

The median age of the patients was 28 years (age range: 1 to 72 years). However, this disease was identified to infect all the age groups. Demographic characteristics of the patients are shown in Table 1. The majority of the patients were infected in autumn (49.2\%); Figure 1 summarizes the number and percentage of patients in different seasons of the year.

Most of the new cases were observed in 2013 with 100 cases $(37.6 \%)$. The second highest incidence rates were in 2014 with 97 patients $(36.55 \%)$ and 2015 with 69 patients $(25.9 \%)$. The highest number of lesions (165) was observed in face, followed by 112,47 , and 13 cases in the hands, legs, and trunk, respectively. The mean number of lesions per patient was reported to be $21.2 \pm 4.46$. In this study, the relationship between age and the location of the lesion was evaluated using Mann-Whitney U test. According to Table 2 , there was a significant relationship between mean age of the patients and location of the lesion (face, hands, and legs).

Table 1. Demographic data in patients with cutaneous leishmaniasis in Zarrin Dasht (2013-2015)

\begin{tabular}{lcc}
\hline & $\mathbf{N}$ & $\mathbf{( \% )}$ \\
\hline Sex & 111 & \\
Male & 155 & 41.7 \\
Female & & 58.3 \\
\hline Age group(yr) & 176 & \\
5-0 & 42 & 66.2 \\
$15-5$ & 15 & 15.8 \\
$30-15$ & 33 & 5.6 \\
$30<$ & 125 & 12.4 \\
\hline Location & 141 & 47 \\
Urban & & 53 \\
\hline Rural & &
\end{tabular}




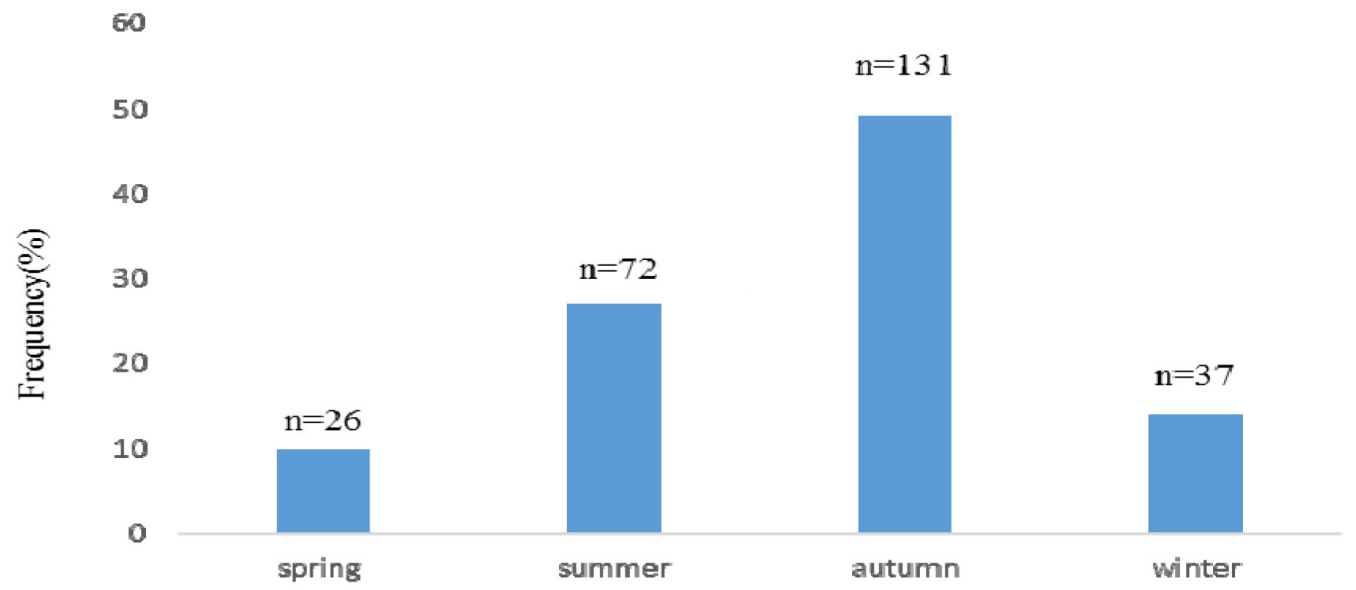

Figure 1. Frequency distribution of patients with cutaneous leishmaniasis based on seasons of occurrence in Zarrin Dasht (2013-2015)

Table 2. Comparison of the mean age based on the location of the lesion in patients with cutaneous leishmaniasis in Zarrin Dasht (2013-2015)

\begin{tabular}{|c|c|c|c|c|}
\hline \multirow{2}{*}{\multicolumn{2}{|c|}{ Location of the lesion }} & \multicolumn{2}{|c|}{ Age } & \multirow{2}{*}{$\boldsymbol{P}$} \\
\hline & & Mean & Median & \\
\hline \multirow{2}{*}{ Face } & Have & 6.28 & 3 & \multirow{2}{*}{$<0.001$} \\
\hline & Have not & 16.01 & 7 & \\
\hline \multirow{2}{*}{ Hands } & Have & 13.02 & 5 & \multirow{2}{*}{$<0.001$} \\
\hline & Have not & 7.77 & 3 & \\
\hline \multirow{2}{*}{ Legs } & Have & 11.45 & 5 & \multirow{2}{*}{0.037} \\
\hline & Have not & 9.66 & 3 & \\
\hline \multirow{2}{*}{ Trunk } & Have & 4.31 & 5 & \multirow{2}{*}{0.623} \\
\hline & Have not & 10.27 & 4 & \\
\hline
\end{tabular}

\section{Discussion}

The results of this study revealed that cutaneous leishmaniasis is an endemic disease in Zarrin Dasht, Fars Province, Iran. A study confirmed that among the 31 provinces of Iran, the highest incidence rates of cutaneous leishmaniasis were observed respectively in Ilam, Fars, and Khorasan Razavi(6); a similar study in Zarrin Dasht showed that cutaneous leishmaniasis is a native disease in this district (9).

In this study, the number of infected cases was higher in rural regions compared to urban areas. In studies performed in Khorasan Razavi and Larestan provinces, it was found that the risk of cutaneous leishmaniasis in rural areas was significantly higher than in urban areas $(10,11)$, which could be due to the existence of old buildings made of clay and hay, livestock and agricultural work, and untreated diseases in rural regions.

In this study, the majority of the affected cases were female. A study conducted in Qom confirms this finding (12). However, it is not in agreement with the findings of studies carried out in Khorasan Razavi and Ilam $(7,8)$. To justify this finding, it could be stated that in rural areas women are more exposed to the disease as they have to take care of livestock and poultry, and there are a lot of sandflies in animal sheds.

The results of this study indicated that the disease 
has been observed in all age groups. However, it is more prevalent in the $0-5$ year age group. This result is consistent with those of previous studies conducted in Shiraz, Gonbad, and Golestan Province $(13,14)$. This finding might be due to the fact that children at this age spend most of their time outdoors; moreover, their clothing make them susceptible to mosquito bites (15).

Herein, the majority of the wounds were respectively found on the face, hands, legs, and trunk. In a study in Bam, Iran, the majority of the lesions were observed in the face (16). Nonetheless, in another study, most of the wounds were on the hands, feet, and face $(12,14)$. Non-covered parts of the body, due to being exposed to the mosquito bites, are more prone to disease.

We found that the disease is most common in autumn and summer. Some studies confirmed this finding and showed the high prevalence of cutaneous leishmaniasis in autumn $(17,18)$. Activity of sandflies in summer and incubation period of the disease till fall may account for this finding (19).

The major limitation of this survey is its relatively small sample size. This study was performed in the town of Zarrin Dasht, Iran. To improve generalizability of the results, we recommend conducting further studies in vaster areas with larger sample sizes.

\section{Conclusion}

Cutaneous leishmaniasis, as one of the most important diseases transmitted by sandflies, is of particular importance due to its high prevalence across the country. According to the available findings, it can be concluded that Zarrin Dasht is a highly endemic area in Fars Province, with 266 infected patients between 2013 and 2015. Yet, the actual number may be higher than this. Therefore, management of cutaneous leishmaniasis should be one of the priorities of centers for national disease control and prevention. Training programs should address environmental health activities including garbage collection, removing construction debris, as well as ways for preventing cutaneous leishmaniasis and its transmission.

\section{Conflicts of interest}

None declared.

\section{Authors' contributions}

F. Nikouee was the chief investigator and principal author of the manuscript. M. Motamed-Jahromi was responsible for preparation of the final manuscript. M. Soltanian proposed the study subject. F. Babaee performed data collection.

\section{Acknowledgements}

This article was extracted from a research project approved by the Deputy of Research at Fasa University of Medical Sciences. We would like to thank all of those who assisted us in performing this study.

\section{References}

1. Postigo JA. Leishmaniasis in the world health organization eastern mediterranean region. Int J Antimicrob Agents 2010; 36(Suppl 1):62-5.

2. Schwartz E, Hatz C, Blum J. New world cutaneous leishmaniasis in travellers. Lancet Infect Dis 2006; 6(6):342-9.

3. Alvar J, Velez ID, Bern C, Herrero M, Desjeux P, Cano J, et al. Leishmaniasis worldwide and global estimates of its incidence. PloS One 2010; 7(5):e35671.

4. Mohebali M. Visceral leishmaniasis in Iran: review of the epidemiological and clinical features. Iran J Parasitol 2013; 8(3):348-58.

5. Shirzadi MR, Gouya MM. National guidelines for cutaneous leishmaniasis surveillance in Iran. Tehran: MoHaME Zoonoses Control Department; 2010. P. 1-78 (Persian).

6. Norouzinezhad F, Ghaffari F, Norouzinejad A, Kaveh F, Gouya MM. Cutaneous leishmaniasis in Iran: results from an epidemiological study in urban and rural provinces. Asian Pac J Trop Biomed 2016; 6(7):614-9.

7. Pagheh AS, Fakhar M, Sharif M, Danesh V, Ahmadi Z. Epidemiological survey of cutaneous leishmaniasis due to leishmania tropica in a new focus in Khorasan Razavi province. J Mazandaran Univ Med Sci 2013; 23(103):4652 (Persian).

8. Roghani AR, Yasemi MR, Jalilian M, Abdi J, Rezai 
Tavirani K. Epidemiology of cutaneous leishmaniasis in Ilam province. Res Med 2013; 36(5):50-3 (Persian).

9. Fakoorziba MR, Baseri A, Eghbal F, Rezaee S, Azizi K, Moemenbellah-Fard M. Post-earthquake outbreak of cutaneous leishmaniasis in a rural region of southern Iran. Ann Trop Med Parasitol 2011; 105(3):217-24.

10. Dehghan A, Ghahramani F, Hashemi B. The epidemiology of anthroponotic cutaneous leishmaniasis (ACL) in Larestan, 2006-2008. J Jahrom Univ Med Sci 2010; 1(8):7-11 (Persian).

11. Fakhar M, Rahmati B. Visceral leishmaniasis in Mazandaran province and review on its current situation in Iran. J Babol Univ Med Sci 2011; 13(2):68-75 (Persian).

12. Rassi Y, Saghafipour A, Abai MR, Oshaghi MA, Mohebali M, Mostafavi R. Determination of leishmania parasite species of cutaneous leishmaniasis using PCR method in central county, Qom province. Zahedan J Res Med Sci 2013; 15(12):13-6.

13. Fakhar M, Mikaeili F, Hatam GR, Habibi P, Karamian M, Motazedian M, et al. A molecular epidemiology survey of cutaneous leishmaniasis in patient referring to parasitology lab at shiraz school of medicine and the importance of PCR assay. J Jahrom Univ Med Sci 2010; 8(1-6):2-6 (Persian).

14. Mesgarian F, Rahbarian N, Mahmoudi Rad M, Hajaran
H, Shahbaz F, Mesgarian Z, et al. Identification of Leishmania species isolated from human cutaneous Leishmaniasis in Gonbad-e-Qabus city using a PCR method during 2006-2007. Tehran Univ Med J 2010; 68(4):250-6 (Persian).

15. Doroodgar A, Mahbobi S, Nemetian M, Sayyah M, Doroodgar M. An epidemiological study of cutaneous leishmaniasis in Kashan (2007-2008). Koomesh 2009; 10(3):177-84 (Persian).

16. Sharifi I, Poursmaelian S, Aflatoonian MR, Ardakani RF, Mirzaei M, Fekri AR, et al. Emergence of a new focus of anthroponotic cutaneous leishmaniasis due to Leishmania tropica in rural communities of Bam district after the earthquake, Iran. Trop Med Int Health 2011; 16(4):510-3.

17. Fathy FM, El-Kasah F, El-Ahwal AM. Emerging cutaneous leishmaniasis in Sirte-Libya: epidemiology, recognition and management. J Egypt Soc Parasitol 2009; 39(3):881-905.

18. Faulde M, Schrader J, Heyl G, Amirih M. Differences in transmission seasons as an epidemiological tool for characterization of anthroponotic and zoonotic cutaneous leishmaniasis in northern Afghanistan. Acta trop 2008; 105(2):131-8.

19. Barati H, Barati M, Lotfi MH. Epidemiological study of cutaneous leishmaniasis in Khatam, Yazd province, 20042013. Paramed Sci Military Health 2015; 10(2):1-5. 